\title{
DESAIN SERIOUS GAME SOSIALISASI BENCANA BERBASIS MODEL TEORI AKTIFITAS
}

\author{
Fresy Nugroho ${ }^{1,2}$, Eko Mulyanto Yuniarno ${ }^{1}$, Mochamad Hariadi ${ }^{1}$ \\ 1) Jurusan Teknik Elektro, Fakultas Teknik Elekto \\ Institut teknologi Sepuluh Nopember Surabaya \\ 2) Jurusan Teknik Informatika, Fakultas Sains dan Teknologi \\ Universitas Islam Negeri Maulana Malik Ibrahim Malang \\ fresy14@mhs.ee.its.ac.id
}

\begin{abstract}
ABSTRAK
Sosialisasi bencana masih mengalami beberapa kendala antara lain kesulitan bila dilakukan secara offfline, mengingat untuk sosialisasi offline membutuhkan waktu khusus, memerlukan persiapan yang lama dan memerlukan alokasi dana khusus. Makalah ini memberikan sebuah pendekatan baru berupa sosialisasi bencana dalam bentuk serious game. Sehingga dinamakan serious game sosialisasi bencana. Dalam mendesain serious game sosialisasi bencana, menggunakan model teori aktivitas utnuk serious game dan tahapan sosialisasi bencana sebagaimana di isyaratkan dalam undang-undang tentang penanggulangan bencana dan diuraikan pusat vulkanologi dan mitigasi bencana geologi. Untuk membuat sebuah serious game dibutuhkan pula metode finite state machine untuk memudahkan mesin mengatur permainan. Visualisasi juga di rancang untuk menunjukkan capaian yang diperoleh pemain agar lebih menarik.
\end{abstract}

Keyword : serious game sosialisasi bencana, model teori aktivitas, tahapan sosialisasi bencana, finite state machine

\section{PENDAHULUAN}

Penanganan krisis bencana alam, terutama kegunungapian dari sisi manfaat dan bencana, sinergi penggunaan teknologi informasi komputer pada setiap tahap penanganan bencana, mulai dari : mitigasi bencana, kesiapan menghadapi bencana, tanggap bencana dan pemulihan pasca bencana, mempunyai peran yang sangat penting, disebabkan fleksibilitas tinggi, yang memungkinkan akses kapan saja, di mana saja dan menggunakan perangkat apa saja (ubiquitous)[1]. Sepanjang dekade terakhir, pusat vulkanologi dan mitigasi bencana geologi (PVMBG) Indonesia dan instansi terkait, sering melakukan sosialisasi tentang krisis letusan gunungapi terhadap sebagian besar sekolah, lingkungan komunitas tertentu, dan kader - kader masyarakat di sekitar gunungapi yang aktif, guna meningkatkan awareness melalui berbagai media, baik media cetak dan media elektronik, termasuk penggunaan website. Hal ini perlu dilakukan, mengingat hasil survey menyatakan, kejadian bencana akibat aktivitas gunung berapi di Indonesia pada tahun 2006-2015, merupakan peringkat ke 4 dari 8 jenis bencana yang sering terjadi di Indonesia, dengan kerugian US\$186.000[2].

Seiring dengan inovasi yang dilakukan, untuk meningkatkan awareness, tidak hanya berupa wajib latih bagi siswa sekolah dan kader - kader masyarakat di sekitar gunungapi yang aktif melalui media buku, pamflet, banner, atau video dan siaran radio saja. Walaupun demikian, hal tersebut masih membutuhkan perbaikan, karena untuk sosialisasi offline, tutor dan siswa bersama-sama harus berada dalam satu kelas khusus. Padahal seharusnya lebih memudahkan peserta sosialisasi dalam memahami dan menyadari pentingnya penanggulangan bencana $[3,4,5,6,7]$.

Salah satu upaya yang dapat di tempuh untuk meningkatkan awareness siswa serta kader - kader masyarakat di sekitar gunungapi yang aktif dan juga kepedulian serta tanggung jawab pendidik tersebut, adalah dengan menjadikan materi sosialisasi ke dalam sebuah model serious game [8] sehingga di sebut dengan Serious Game Sosialisasi Bencana (SGSB). Serious game sosialisasi bencana dirancang untuk tujuan menumbuhkan pengetahuan, keterampilan dan merangsang serta meningkatkan kesadaran (awareness) baik secara kognitif, emosional maupun perilaku (behavior) pada pemain, menggunakan berbagai macam platform PC, perangkat Mobile, online maupun offline $[9,10,11,12,13]$. Beberapa penelitian tentang serious game untuk meningkatkan awareness sudah dilakukan, seperti serious game untuk mengenalkan konsep awareness pada lingkungan sosial [14]. Penelitian lain yang merupakan bentuk serious game untuk meningkatkan awareness tentang kultur dan etiket Jepang [15], serious game untuk meningkatkan awareness bidang sosial dalam tindakan untuk mencegah bencana[16]. Serious game untuk meningkatkan awareness tentang penyakit alzheimer [17].

Harapan yang ingin dicapai adalah, dengan model SGSB, diperoleh kesadaran dan pemahaman, bagaimana harus bersikap atau mengambil keputusan dengan tepat berdasarkan informasi area dan hal-hal yang berkaitan dengan ruang tertentu $[18,19,20]$. Dalam mendesain SGSB, dilakukan 
berdasarkan pendekatan model teori aktivitas, yang memadukan sisi pembelajaran, game dan instruksional $[21,22,23]$ dan tahapan sosialisasi bencana[7].

Komponen pembentuk game, pada umumnya terdiri dari terrain (lingkungan bermain), quest (misi), score, scenario dan non player character (NPC). NPC merupakan aktor dalam game yang dapat menentukan pilihan, pergerakan, mengejar pemain, menyerang dan menghindar. Tentunya dalam SGSB yang didesain ini berbeda, karena NPC tidak bersifat menyerang pemain, namun lebih bersifat sebagai teman pemain yang harus ditingkatkan awarenessnya. Dalam SGSB ini, parameter awareness NPC yang diharapkan meningkat adalah pengetahuan, pemahaman, kesadaran dan perilaku tanggap bencana[7]. Bencana yang digunakan sebagai konten dalam SGSB adalah bencana gunung meletus.

Selanjutnya dibentuk perilaku NPC berupa hubungan antara awareness NPC dengan parameter model teori aktivitas untuk SGSB[21]. Metode artificial intelligence (AI) dibutuhkan dalam proses pembuatan perilaku NPC. Metode AI yang diajukan dalam menjembatani perilaku NPC dan model teori aktivitas adalah Finite State Machine[24].

Makalah ini mengulas penerapan kombinasi model teori aktivitas dan tahapan sosialisasi bencana. Pembahasan analisis dan framework yang diperoleh dari metode yang diusulkan dan implementasinya dibahas pada bab 2 . Bab 3 berisi kesimpulan dan penelitian lebih lanjut.

\section{A. Desain Serious Game Sosialisasi Bencana}

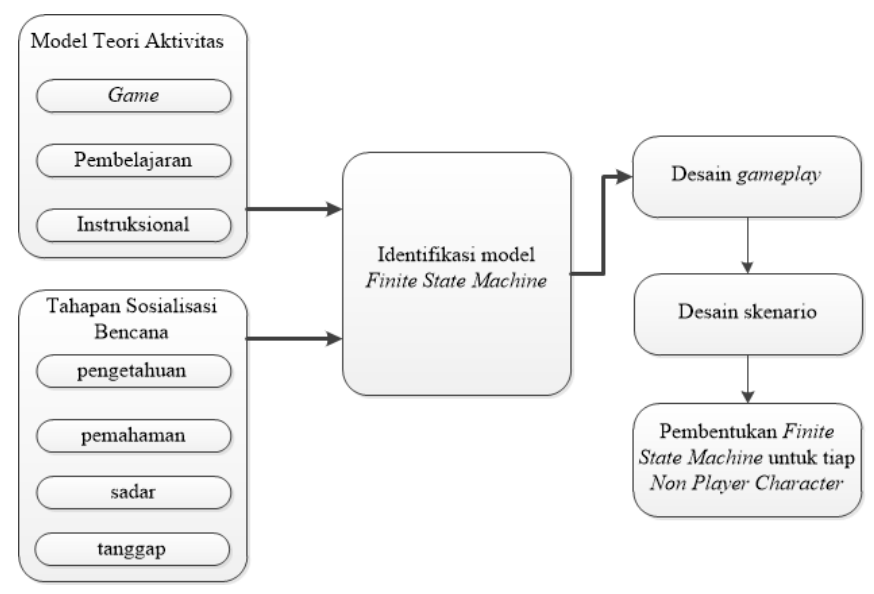

Gambar 1. Model Serious Game Sosialisasi Bencana (SGSB)

Dalam mendesain SGSB, dilakukan berdasarkan pendekatan model teori aktivitas, yang memadukan sisi pembelajaran, game dan instruksional [21,22,23] dan tahapan sosialisasi bencana[7] yang terdiri dari pengetahuan tentang bencana, pemahaman tentang bencana, sadar resiko bencana dan tanggap bencana. Tahap untuk membentuk SGSB terdiri dari tahap identifikasi model finite state machine untuk membangun hubungan pemain game dengan NPC. Tahap desain gameplay saat bermain. Tahap desain skenario. Dan pembentukan finite state machine untuk setiap NPC. Sebagaimana diperlihatkan dalam Gambar 1.

\section{B. Desain gameplay}

Perumusan gameplay pada game "Serious Game Sosialisasi Bencana (SGSB)" berupa aturan, yaitu :

1. Permainan bersifat single player yaitu hanya dimainkan oleh satu pemain.

2. Permainan bergenre First Person Shooter.

3. Permainan terdiri dari 5 lokasi yaitu kamar tidur, ruang kelas, perpustakaan, aula, lapangan sekolah dan laboratorium.
4. Pemain akan memainkan karakter utama yang bernama Nazim dengan melakukan interaksi terhadap NPC.

5. NPC terdiri dari guru (NPC-A) dan teman karib Nazim adalah Via(NPC 1), Mepi(NPC 2), dan Abdul(NPC 3).

6. Pemain dapat melakukan interaksi dengan NPC dengan cara menjalankan Nazim hingga bersentuhan dengan NPC.

7. Pemain dan NPC memiliki lima kemampuan yang harus dipenuhi, yaitu pengetahuan, pemahaman, sadar, tanggap dan sosialisasi.

8. Pemain harus meningkatkan kemampuan yang dimiliki, yang terdiri dari kemampuan pengetahuan, pemahaman, sadar dan tanggap yang dilakukan dengan melakukan interaksi dengan guru (NPC-A) hingga mencapai kategori cukup untuk seluruh empat kemampuan.

9. Untuk kemampuan sosialisasi, dilakukan dengan melakukan interaksi pada NPC 1, NPC 2 dan NPC 3.

10. Setelah pemain meningkatkan pengetahuan, pemahaman, sadar, dan tanggap bencana maka pemain harus melakukan interaksi dengan NPC 
1 hingga NPC 3 agar pemain dapat menyelamatkan ketiga temannya dari bencana gunung meletus.

11. Pemain harus berhasil meningkatkan kemampuan NPC 1 hingga NPC 3 selama gunung belum meletus, yaitu selama 30 hari dalam waktu game.

12. Pemain hanya dapat berpindah lokasi sebanyak 3 kali dalam 1 hari permainan.

\section{Desain Skenario}

Game ini mempunyai cerita utama tentang karakter laki-laki bernama Nazim (pemain) kelas 4 sekolah dasar, dekat lokasi gunung yang berstatus aktif. Nazim berkeinginan untuk menjadi hero di sekolahnya, sebagai penyelamat dari erupsi gunungapi. Oleh karena itu Nazim berkeinginan untuk menguasai segala hal tentang erupsi gunung meletus dan tetap survive setelah bencana gunung meletus. Selain itu, Nazim juga berambisi untuk menyelamatkan teman-teman karibnya. Terdapat tiga karakter teman dekatnya yang selalu bermain bersamanya. Yaitu Via (NPC 1) yang gemar belajar, Mepi yang suka mengamati alam (NPC 2), dan Abdul yang gemar olahraga(NPC 3).

\section{Pembentukan Finite State Machine (FSM)}

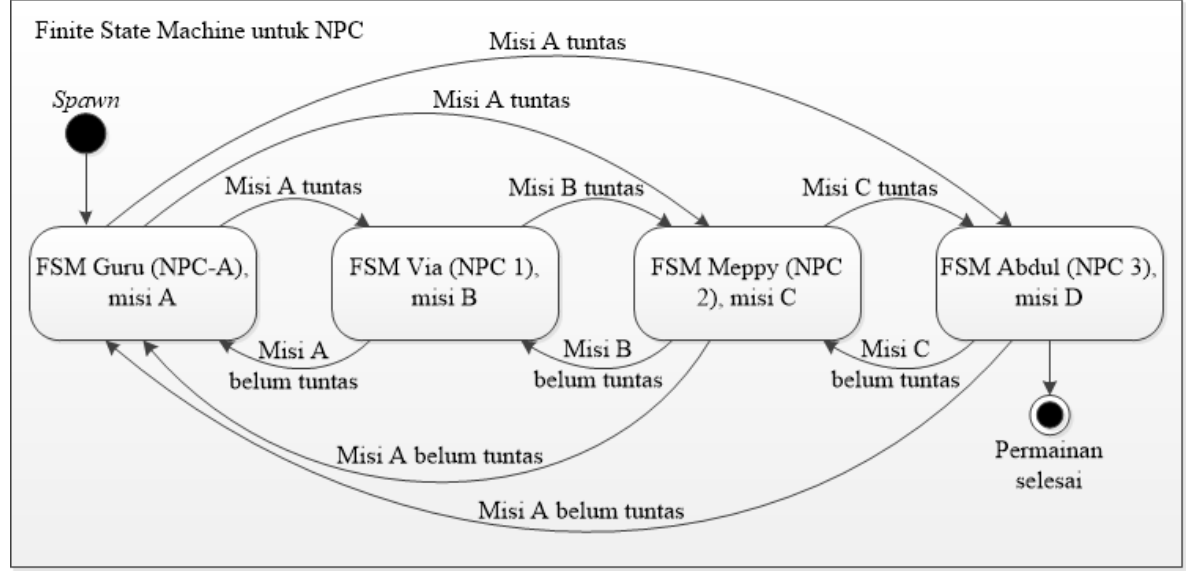

Gambar 2. Pembentukan FSM untuk NPC

Diawali dengan spawn, pemain masuk ke dunia SGSB setelah melewati menu utama. Tugas pemain adalah menuntaskan misi A. Hal ini dilakukan dengan pemain menjawab seluruh pertanyaan yang disampaikan guru (NPC-A). Pertanyaan yang diberikan berupa puzzle yang harus diselesaikan pemain. Apabila guru menyatakan bahwa pemain sudah memenuhi misi A, maka dipersilahkan melanjutkan ke misi berikutnya. Pemain dapat memilih misi yang di inginkan. Jadi dari misi A, pemain dapat melanjutkan ke misi B, atau misi $C$ atau misi D. Setiap misi lanjutan yang dipilih pemain, diharapkan pemain memainkan hingga tuntas. Bila pemain belum memenuhi ketuntasan misi yang dipilih, maka FSM akan memberikan pilihan untuk melanjutkan permainan atau keluar dari permainan. Bila pemain memilih melanjutkan permainan, dan pemain belum menuntaskan misi yang dipilih, maka FSM akan mengarahkan pemain ke misi sebelumnya. Bila pemain dapat memenuhi seluruh misi yang di berikan, maka permainan selesai. Pada akhir permainan, maka SGSB akan memberikan hasil pencapaian yang diperoleh pemain. Semakin banyak misi yang dipenuhi maka nilai yang diperoleh pemain semakin tinggi. Dan nilai yang diberikan terdiri dari kemampuan pengetahuan, pemahaman, sadar, tanggap dan sosialisasi. Pada akhir permainan juga ditunjukkan nilai dari masing - masing NPC. Sebagaimana diperlihatkan dalam Gambar 2. 


\section{E. Desain kemampuan untuk pemain dan NPC 1 hingga NPC 3}

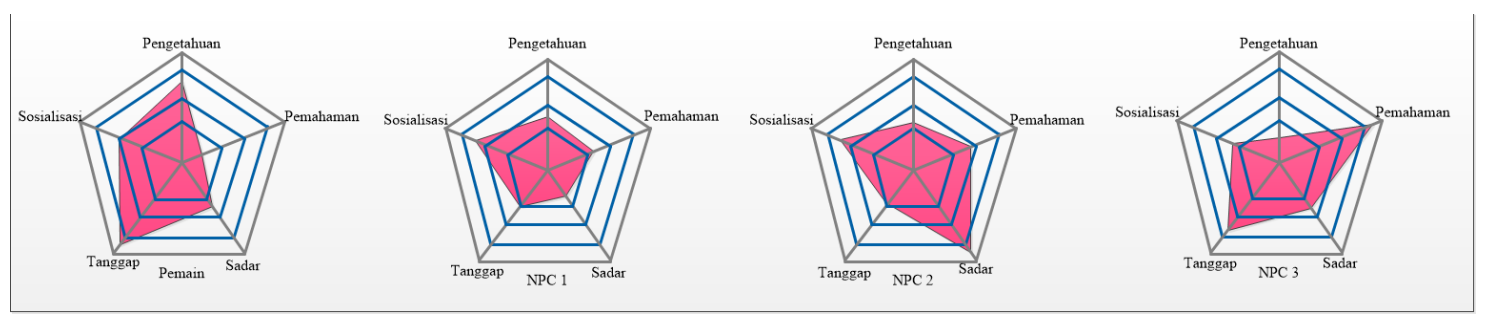

Gambar 3. Kemampuan untuk pemain dan NPC 1 hingga NPC 3

Pada saat bermain, pemain dan NPC memiliki lima kemampuan. Dimana kemampuan itu terdiri dari pengetahuan bencana, pemahaman bencana, sadar bencana, tanggap bencana dan sosialisasi bencana. Pengaturan besar kecilnya kemampuan awal pemain dan NPC dilakukan secara acak. Sebagai contoh, seperti diperlihatkan dalam Gambar 3 , pemain dianggap memiliki pengetahuan sedikit, pemahaman kurang, sadar bencana rendah, tanggap cukup dan sosialisasi kurang. NPC 1 memiliki kemampuan sosialisasi sedang, namun pengetahuan, pemahaman, sadar dan tanggap yang rendah, sehingga merupakan tantangan bagi pemain untuk dapat meningkatkan karakter yang kurang tersebut. NPC 2 sudah memiliki sadar bencana dan sosialisasi yang cukup, namun rendah pada pengetahuan, pemahaman dan tanggap. Sedangkan NPC 3 sudah memiliki pemahaman tinggi, namun pengetahuan, sadar, tanggap dan sosialisasi rendah. Peningkatan seluruh kemampuan NPC 1 hingga NPC 3 dapat dilakukan bila pemain sudah mencapai kategori cukup pada semua kemampuan. Peningkatan kemampuan NPC 1 hingga NPC 3 dilakukan dengan terjadinya dialog antara pemain dengan NPC 1 hingga NPC 3.

\section{PEMBAHASAN}

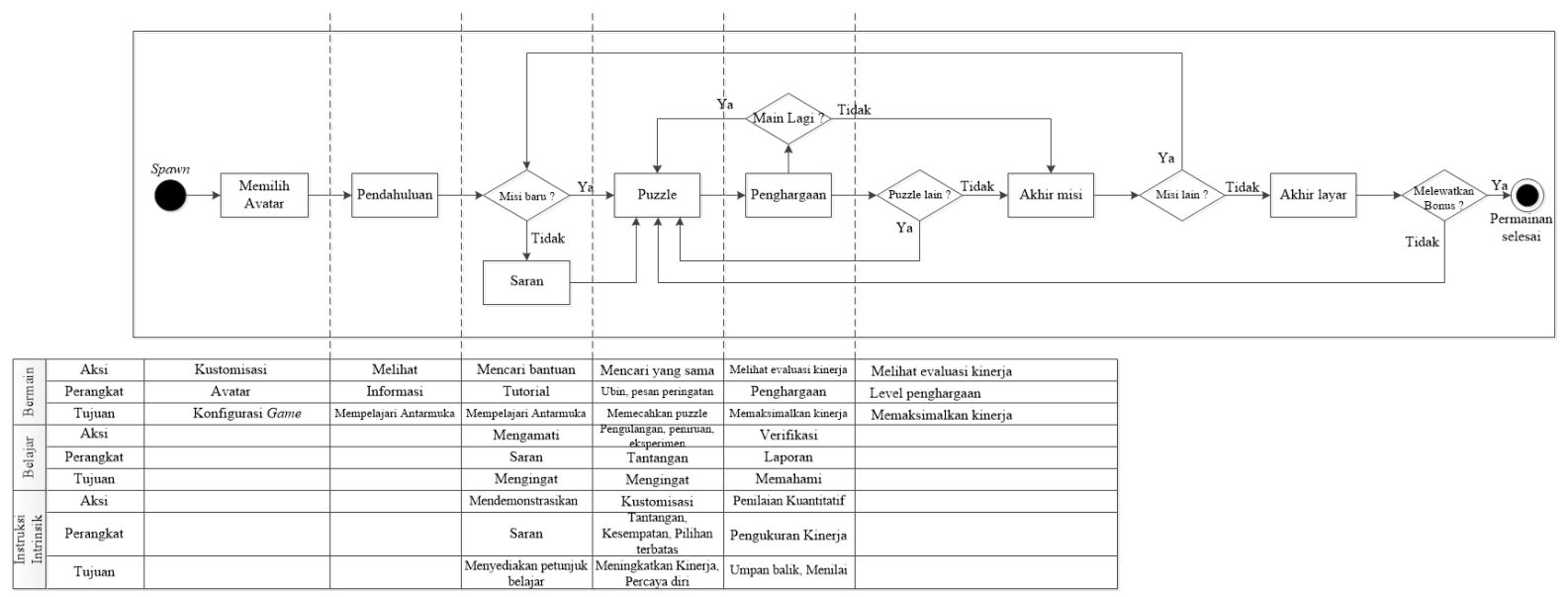

Gambar 4. Pemetaan model teori aktivitas dan gameplay

Hubungan kombinasi metode berbasis teori aktivitas untuk SGSB, dengan gameplay ditunjukkan dalam Gambar 4. Berdasarkan Gambar 4, maka setelah pemain masuk ke permainan, maka dari sisi bermain, pemain diminta melakukan aksi berupa kustomisasi atau memilih model avatar yang akan diperankan pemain, perangkat yang disediakan permainan adalah avatar yang akan dimainkan dengan tujuan melakukan konfigurasi permainan. Selanjutnya menuju tahap pendahuluan, pada tahap ini, berdasarkan model teori aktivitas, pemain akan melakukan sisi bermain. Yang terdiri dari aksi yaitu melihat, perangkat dalam permainan berupa informasi yang disajikan pada pemain, dengan tujuan pemain mempelajari antarmuka yang ada dalam permainan. Pada tahap berikutnya, pemain akan dihadapkan pada pilihan untuk memilih misi baru atau tidak. Bila pemain memilih misi baru, pemain akan memainkan puzzle atau masuk ke misi A sesuai dengan Gambar 2. Bila pemain memilih tidak memilih misi baru, maka permainan akan memberikan saran, selanjutnya permainan akan mengarahkan pemain untuk memainkan puzzle atau masuk ke misi A. Pada tahap selanjutnya, yaitu penghargaan, permainan akan memberikan penghargaan berupa penambahan nilai, penambahan 
kemampuan pemain, serta bonus yang lain. Setelah menerima penghargaan, pemain dihadapkan pada pilihan main puzzle yang sama, atau pilihan bermain puzzle jenis lain. Bila dipilih main lagi untuk jenis puzzle yang sama, maka pemain akan memiliki kesempatan meningkatkan penghargaan yang telah diperoleh hingga mencapai nilai maksimal. Bila pemain memilih untuk memainkan jenis puzzle yang lain, maka pemain berkesempatan untuk meningkatkan kemampuan dalam tahapan sosialisasi. Berdasarkan model teori aktivitas, maka pemain berada pada tiga sisi sekaligus, yaitu sisi bermain, belajar dan instruksi intrinsik. Pada sisi bermain, aksi yang dilakukan pemain adalah mencari bantuan, perangkat yang disediakan permainan adalah tutorial permainan dengan tujuan mempelajari antarmuka permainan. Pada sisi belajar, aksi yang dilakukan pemain adalah mengamati, perangkat yang disediakan permainan berupa saran untuk menuntaskan permainan, dengan tujuan pemain mengingat tutorial yang diberikan. Pada sisi instruksi intrinsik, pemain mendemonstrasikan, dengan perangkat berupa saran untuk dipenuhi, dengan tujuan menyediakan petunjuk belajar pada pemain. Hal ini dilanjutkan pemain menuju tahap bermain puzzle, dengan uraian sebagaimana diperlihatkan dalam Gambar 4. Begitu seterusnya hingga permainan selesai.

\subsection{Finite state machine untuk NPC}

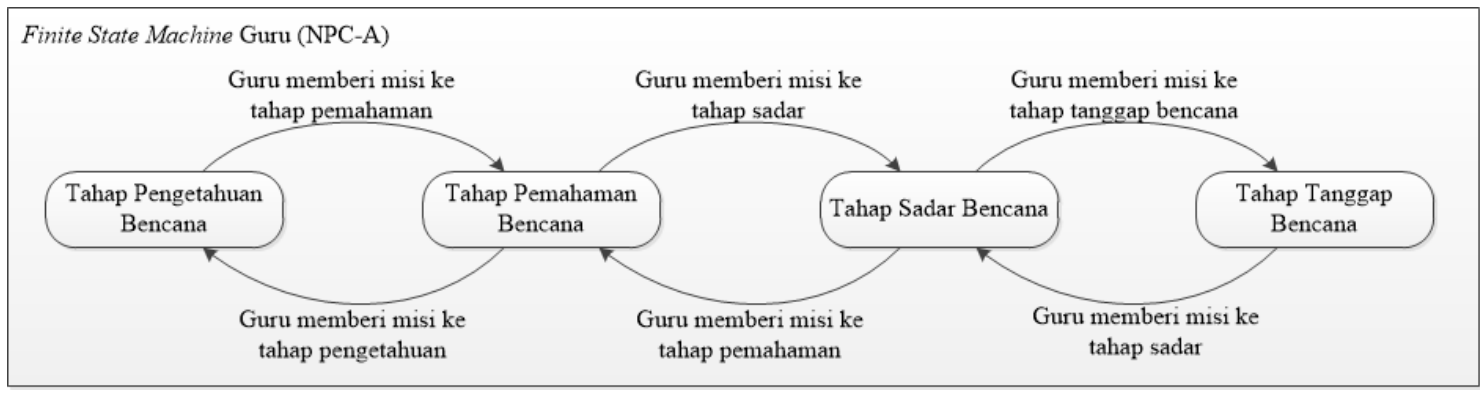

Gambar 5. FSM guru (NPC-A)

Setiap FSM untuk NPC memiliki lima tahap FSM, yaitu tahap pengetahuan bencana, tahap pemahaman bencana, tahap sadar bencana dan tahap tanggap bencana. Sebagai contoh, diperlihatkan dalam Gambar 5, yaitu FSM untuk guru (NPC-A). Perpindahan tahap dilakukan berdasarkan pemenuhan standar yang sudah ditentukan. Misalkan dari tahap pengetahuan bencana, untuk pindah ke tahap pemahaman bencana, dilakukan setelah guru (NPC-A) memberi misi lanjutan yang harus dicapai. Guru (NPC-A) memberi misi lanjutan ke tahap pemahaman bencana bila pemain sudah melengkapi kemampuan dari sisi pengetahuan. Bila setelah masuk tahap pemahaman bencana, ternyata ada quiz atau puzzle yang tidak dapat diselesaikan pemain, maka guru (NPC-A) akan memberikan misi pada pemain untuk kembali ke tahap pengetahuan. Tahap ini berlanjut hingga pemain dapat menyelesaikan semua quiz atau puzzle yang diberikan oleh guru (NPC-A).

Selanjutnya, ditunjukkan FSM untuk guru (NPC-A) untuk tahap pengetahuan bencana sebagai uraian lebih detail dari Gambar 5, seperti diperlihatkan dalam Gambar 6. Pada tahap pengetahuan bencana, guru (NPC-A) berjalan berkeliling area permainan. Hingga guru melihat pemain dalam jarak pandang. Kemudian guru akan mendekati pemain, dilanjutkan dengan memberi misi untuk mencari 5 literatur yang berkaitan dengan bencana. Bila pemain sudah mendapatkan lima literatur yang di minta guru, maka guru akan memberikan quiz atau puzzle. Setelah pemain menjawab quiz atau puzzle, guru akan men-cek jawaban yang diberikan pemain. Bila jawaban pemain sudah tepat, maka guru akan memberikan tugas selanjutnya dan menyimpan hasil jawaban pemain, kemudian pemain diminta untuk melanjutkan permainan ke tahap pemahaman bencana. Bila jawaban pemain tidak tepat, maka guru akan meminta pemain mencari literatur yang sesuai dengan pertanyaan quiz atau puzzle yang diberikan. 


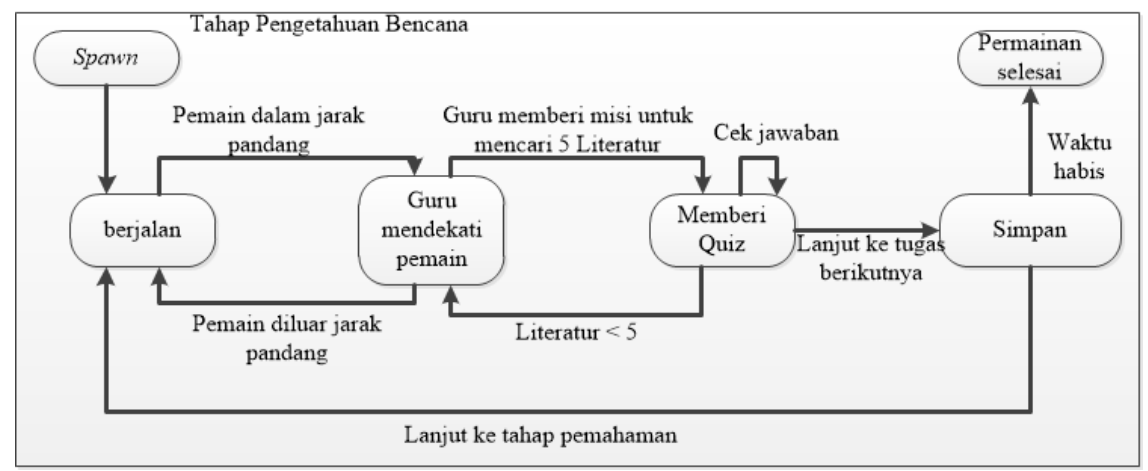

Gambar 6. FSM guru (NPC-A) untuk tahap pengetahuan bencana

Berikutnya diperlihatkan ilustrasi tampilan Serious game Sosialisasi Bencana yang dibuat. Pada Gambar 7. Tampak bahwa permainan yang di desain terdiri dari beberapa parameter, yaitu parameter kesehatan, waktu yang tersisa, skor, pertanyaan, pilihan jawaban dan permainan berikutnya.

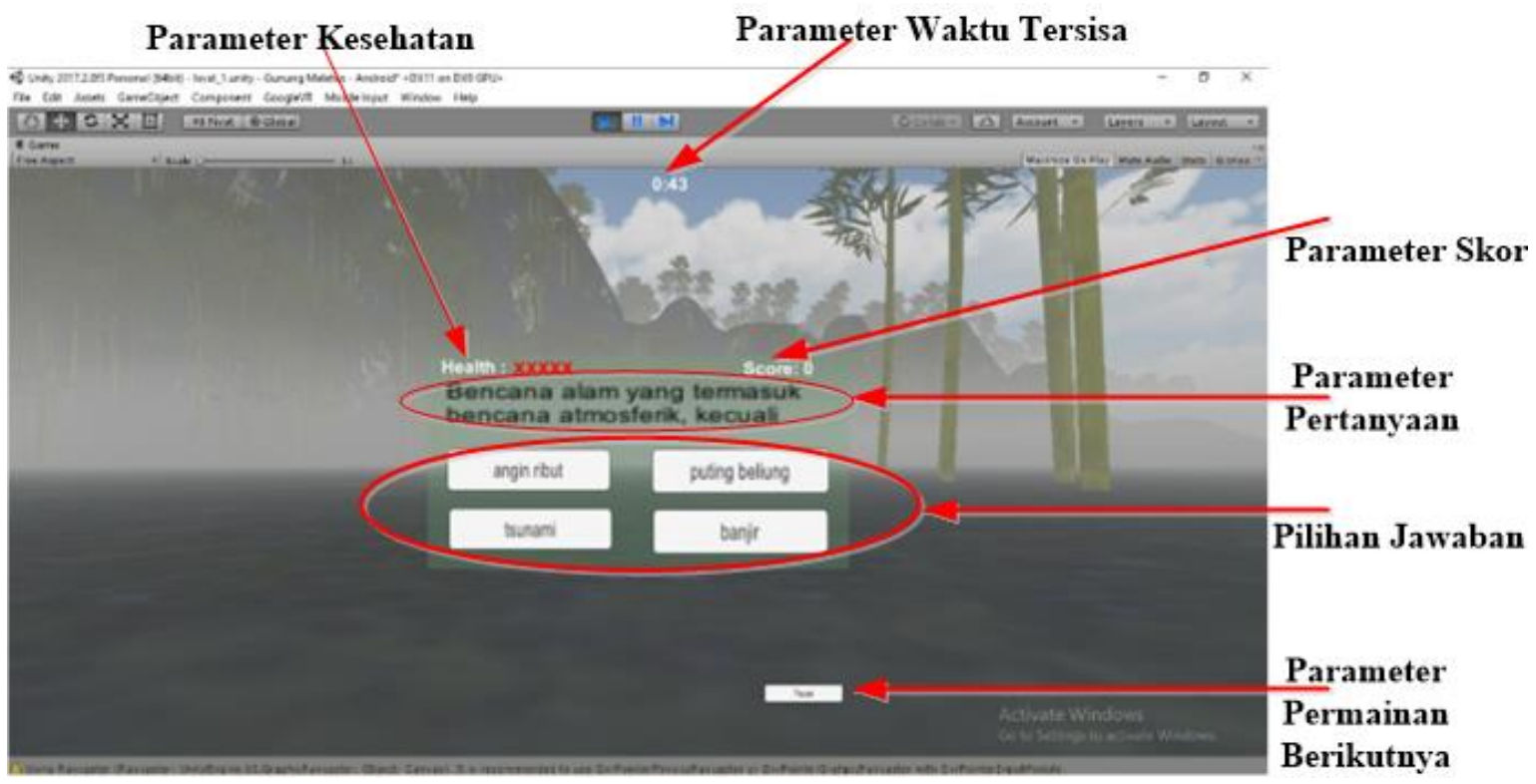

Gambar 7. Ilustrasi tampilan Serious Game Sosialisasi Bencana (SGSB)

\subsection{Perubahan pada pemain atau NPC}

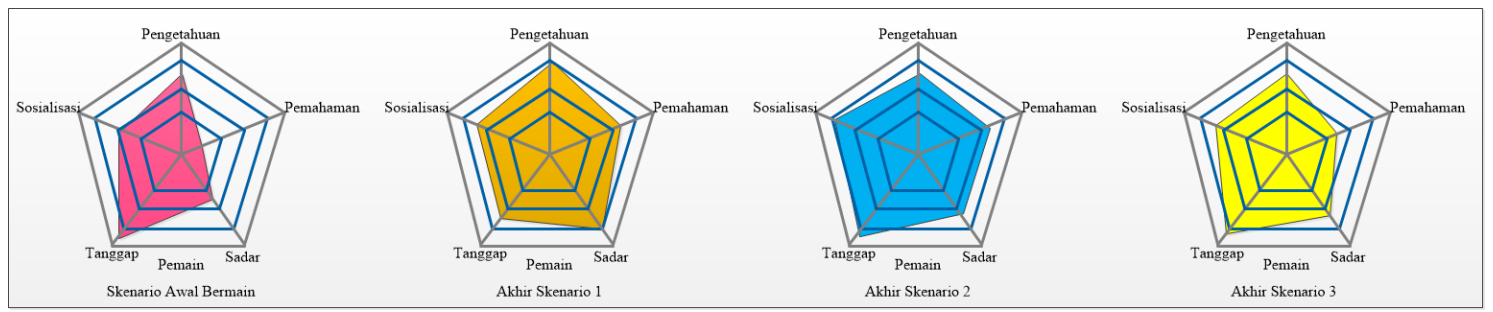

Gambar 8. Visualisasi kemampuan pemain

Pada akhir permainan, akan ditunjukkan capaian yang diperoleh oleh pemain dan NPC 1 hingga NPC 3 dari sisi lima kemampuan.Yaitu kemampuan pengetahuan bencana, pemahaman bencana, sadar bencana, tanggap bencana dan sosialisasi bencana. Sebagai contoh, pada Gambar 7 diperlihatkan beberapa capaian pemain untuk skenario yang berbeda. Dimana, pemain diberikan kemampuan secara acak sebagaimana skenario awal bermain. Setelah pemain menyelesaikan permainan (skenario 1) divisualisasikan capaian pemain untuk skenario 1. Bila pemain bermain lagi, maka capaian 
yang diperoleh ditunjukkan pada akhir skenario 2 . Selanjutnya bila pemain masih ingin bermain lagi, maka capaian pemain ditunjukkan pada akhir skenario 3.

\section{KESIMPULAN}

Berdasarkan penelitian yang dilakukan diperoleh beberapa simpulan sebagai berikut :

1. Model teori aktivitas sangat sesuai bila diterapkan pada serious game, dan model ini tepat untuk mengadopsi tahapan yang dibutuhkan pada sosialisasi bencana.

2. Finite state machine yang dirancang, sudah sesuai dengan model teori aktivitas dan tahapan yang dibutuhkan pada sosialisasi bencana.

3. Visualisasi capaian pemain, akan memberikan kesadaran kepada pemain tentang perlunya mempelajari tahapan sosialisasi bencana.

4. Berikutnya, penelitian akan difokuskan pada penerapan materi pembelajaran berupa mata pelajaran ilmu pengetahuan alam, lebih spesifik lagi ilmu pengetahuan alam untuk kelas 4 sekolah dasar guna memudahkan sosialisasi dan memberikan pemahaman fenomena bencana alam gunungapi. Yang mana mata pelajaran yang di masukkan dalam serious game sosialisasi bencana memiliki indikator dari sisi kognitif, afektif dan psikomotorik siswa. Serta desain akan mempertimbangkan pula kondisi kematangan siswa kelas 4 sekolah dasar. Selanjutnya desain serious game sosialisasi bencana akan diujicobakan pada siswa kelas 4 sekolah dasar.

5. Akan lebih tepat sasaran bila serious game sosialisasi bencana yang dibuat, dibentuk untuk platform android agar bersifat ubiquitous, bersifat multiplayer game agar siswa menemukan tantangan yang lebih nyata dan guru dalam kelas dapat mengamati perkembangan siswa setelah bermain serious game, hasil capaian siswa disimpan dalam database khusus.

\section{Daftar Pustaka}

[1]. J. L. Ph, "Risk Management based on IC Technology in Korea," 2015.

[2]. Center for Excellence in Disaster Management and Humanitarian Assistance, "Indonesia Disaster Management Reference Handbook 2015," J. Chem. Inf. Model., vol. 53, no. 9, pp. 1689-1699, 2015.

[3]. B. Dalgarno and M. J. W. Lee, "What are the learning affordances of 3-D virtual environments?," vol. 41, no. 1, pp. 10-33, 2010.

[4]. H. Slater, N. Davies, S. Burgess, H. Slater, N. Davies, and S. Burgess, "Do teachers matter? Measuring the variation in teacher effectiveness in England Do teachers matter? Measuring the variation in teacher effectiveness in England," no. January, 2009.
[5]. M. Wrzesien and M. A. Raya, "Computers \& Education Learning in serious virtual worlds : Evaluation of learning effectiveness and appeal to students in the E-Junior project," vol. 55, pp. 178-187, 2010.

[6]. Y. Findawati, "Bahan Ajar Multimedia Interaktif Kewirausahaan SMK Menggunakan model Pembelajaran Problem Based Learning," J. Nas. Tek. Elektro dan Teknol. Inf. JNTETI, Vol. 3, No. 4, Novemb. 2014, vol. 3, no. 4, 2014

[7]. Andreastuti, S.D., 2008. Laporan Tanggap Darurat Letusan G. Api, G. Soputan, Sulawesi Utara. Yayasan Media Bhakti Tambang. Bandung.

[8]. D. Eridani, P. I. Santosa, and R. Ferdiana, "Implikasi Game Edukasi 2D dan 3D: Mengenal Huruf dan Angka Terhadap Anak," J. Nas. Tek. Elektro dan Teknol. Inf. Vol. 3, No. 1, Februari 2014, vol. 3, no. 1, pp. 1-5, 2014.

[9]. Abt C., Serious Games, New York, Viking Press, 1970.

[10]. Djaouti D., Alvarez J., Jessel JP, "Classifying Serious Games: The G/P/S Model" Patrick Felicia (ed), "Handbook of Research on Improving Learning and Motivation through Educational Games: Multidisciplinary Approaches", IGI Global, 2011.

[11]. F. Bellotti, B. Kapralos, K. Lee, P. Morenoger, and R. Berta, "Assessment in and of Serious Games: An Overview," vol. 2013, 2013.

[12]. C. K. Chang, Y. T. Tsai, and Y. L. Chin, “A Visualization Tool to Support Analyzing and Evaluating Scratch Projects," in 2017 6th IIAI International Congress on Advanced Applied Informatics (IIAI-AAI), 2017, pp. 498-502.

[13]. H. A. L. Osman, H. Dong, and S. Member, "Ubiquitous Biofeedback Serious Game for Stress Management," vol. 4, 2016.

[14]. J. M. Linssen and T. de Groot, "AGENT: Awareness Game Environment for Natural Training," in Proceedings of the International Conference on the Foundations of Digital Games, Society for the Advancement of the Science of Digital Games, 2013, pp. 433-434.

[15]. C. E. Catalano, A. M. Luccini, and M. Mortara, "Best Practices for an Effective Design and Evaluation of Serious Games," vol. 1, no. 1, 2014.

[16]. A. F. S. Barbosa, P. N. M. Pereira, J. A. F. F. Dias, and F. G. M. Silva, "Serious Games," vol. 2014, 2014.

[17]. B. Cook and P. Twidle, "Increasing Awareness of Alzheimer's Disease through a Mobile Game," in 2016 International Conference on Interactive Technologies and Games, iTAG 2016, Notthingham, United Kingdom, October 26-27, 2016, pp. 55-60. 
[18]. İ. Varank, "Eurasia Journal of Mathematics, Science and Technology Education," Eurasia J. Math. Sci. Technol. Educ., vol. 2, no. 3, 2006.

[19]. D. J. Pucel and T. F. Stertz, "Effectiveness of and Student Satisfaction with Web-Based Compared to Traditional In-service Teacher Education Courses," J. Ind. Teach. Educ., vol. 42, no. 1, pp. 7-23, 2005.

[20]. T. L. Larkin, "Session LEARNING STYLE IN THE CLASSROOM : A RESEARCHGUIDED APPROACH," in International Conference on Engineering and Computer Education, 2003, pp. 1-8.

[21]. M. B. Carvalho, Serious Games for Learning: A model and a reference architecture for efficient game development. 2016.
[22]. Anderson, L., Krathwohl, R., Airasian, P., Cruikshank, K., Mayer, R., Pintrich, P., Raths, J., \& Wittrock, M. (Eds.) (2001). Taxonomy for Learning, Teaching, and Assessing: A Revision of Bloom's Taxonomy. New York, NY: Longman.

[23]. Prajana Marwan Sejati, Pengembangan Buku Teks Tentang Mitigasi Bencana Erupsi Gunungapi Dalam Pembelajaran IPA Kelas 4 SDN Kiyaran 2 Sleman Yogyakarta, skripsi, 2015.

[24]. Miftah Fauzan Rahadian, Addy Suyatno, Septya Maharani, Penerapan Metode Finite State Machine pada Game "THE RELATIONSHIP", Jurnal Informatika Mulawarman, Vol. 11 No.1 Februari 2016. 